\title{
The Internet as a Tool for Communication in Design Projects
}

Hilary Grierson, Research Fellow,

Centre for Academic Practice, and

Department of Architecture \& Building Science.

University of Strathclyde.

emailh.j.grierson@strath.ac.uk

\section{Introduction}

When entering a modern design practice, architecture \& design students must not only be skilled in current CAD applications but must also be familiar in the transfer and organisation of information and data on the Internet. Similarly, the PgDip in Computer Aided Building Design at the University of Strathclyde addresses not only the conventional spread of CAD tools but also investigates the promise of collaborative design through on-line communications and the sharing of project data. This aspect of technology forms the core of the Internet \& WWW Module within which the aim is to investigate the strengths and weaknesses of the Internet as a design communication medium and also to promote group working, peer learning and the development of students' ICT and organisational skills, while also encouraging co-operative and collaborative working. Building on knowledge gained from the ICON projects [1] [2], the Internet Design Project (IDP) was first conceived and offered to students at the end of 1999.

\section{The Project and Teaching Methods}

This case study will concentrate on the initial offerings of the IDP with more recent developments being highlighted throughout the text where appropriate. A prerequisite for this project is that all students should have a relative standard of IT expertise. While some incoming students might be proficient in modelling or drafting it has proven to be advantageous to schedule this module towards the end of the first semester of studies so as to ensure that all participants can draw on a similar raft of expertise. By this stage the preceding class modules have addressed basic CAD skills in 2D and 3D graphics, image processing and webpage design. This should equip them with the skills required to establish a "point of presence" on the Internet, establish their "virtual design practice" and publish the outcomes of the design project on-line.

Each year the CABD class, of anywhere between 30 and 45 students, is split into groups (design teams) of about four. Harasim et al [3] note the importance of group size when designing collaborative activities. Too many participants may mitigate against effective decision making, particularly in an asynchronous environment. They suggest that having three to four members in a group is manageable. In previous years we have allowed groups of five students to work together and found that with the increase in numbers the dynamics within the group become too complex to manage, resulting in weaker group work and lower standards.

Over four weeks, each of the groups, with a tutor acting as the client, was required to -

- engage in online dialogue to formulate a brief detailing a studio and living accommodation for an artist (the client) using email (one week);

- develop outline/scheme design proposals using internet communication technologies (within the group and with the client) (two weeks);

- maintain a web log of communications and design development (in both text and image format) (continuously);

- construct a web diary of daily events including communications;

- prepare and make a formal web presentation of a design solution to a client (and the other groups) using internet technologies (one week).

The pedagogic approach was one of problem-based learning supported at key points by lectures on basic content and theory. Group working seminars and tutor-led demonstrations of the communications software were also conducted. Leading experts from practice and software vendors were invited to make presentations to the students to highlight current use in practice. Peer learning was a significant element; learner to learner interaction being encouraged as a central feature of the learning process. Moore [4] notes three types of interaction which take place within remote and distance education, learner-content, learner-instructor and learnerlearner interaction. This third form of interaction, learner-learner, can occur without the constant presence of an educator.

The assessment criteria for the project was based around the design quality of the final web presentation along with a review of the success (or otherwise) of each group's interaction and the quality of the final design 
proposals. Team work is evidenced through the web diaries which also indicated how the work had been shared and who took on each of the required responsibilities.

The IDP learning outcomes presented to the students were -

- to be able to communicate effectively using Internet technologies;

- to be able to critically assess the strengths and weaknesses of the technology employed;

- to be able to conduct formal and informal dialogues both internally within the design team and externally with the client to produce a design brief and consequent solution;

- to be able to apply software tools creatively to the design and presentation of an agreed design solution; and

- to understand the dynamics of group working and design within a group.

\section{Technologies Used}

Technologies were initially 'very low tech'; the aim being to keep the equipment and infrastructure as 'invisible' as possible -

- University \& home email

- Microsoft's 'Netscape Communicator' v4.7 (pc platform) desktop conferencing for -

- text based communications

- $\quad$ file/document transfer

- $\quad$ whiteboard (for marking up drawings)

- $\quad$ audio \& video desktop conferencing (more recently).

Students had prior basic knowledge of the necessary software used to create text, drawings, images and models Microsoft Office, Adobe PhotoShop, FormZ (3D modeller), AutoCAD and Adobe PageMill (web editor) from previous classes on the course. This software was available to the students on 20 Pentium PCs and 20 iMacs in two Departmental labs. The groups tended to carry out designing in a traditional manner, sketching on paper and then scanning these sketches as Jpegs which were circulated electronically or used in real time sessions. Many students purchased their own educational copies of FormZ (since this was one of the component tools of the course) for their PCs at home; all had Microsoft Office and some form of image editing tool and several had access to AutoCad at their part-time place of work. In earlier years students carried out the web page design at university using PageMill but more sophisticated software like Dreamweaver is preferred by the students now on a downloadable thirty day trial at home.

Any staff training in connection with the project was on a self-taught basis and all testing of the communications software prior to implementation was undertaken in mini trials with a few willing student volunteers. Technical support was available from a technician and within tutor team expertise.

\section{Email}

E-mail and file attachments were initially used, to establish a brief between the design team and the client. This proved an easy introduction to the project as all students were familiar with email capabilities. Most had email accounts at home and some groups set up specific e-mail accounts for the purpose of the IDP. Clients pulled images from the Web to illustrate precedents, preferred styles and material choices which were then sent to their design team. Jpegs of proposals were imported into Word, annotated and emailed back to the client for comment.

It was noticeable that the students were 'chatty' and informal when using email to communicate within the groups ie student to student. However, when communicating with the client the electronic dialogue became far more formal. The students accounted this to their perceptions of the appropriate type of dialogue expected in practice between a designer and a client. But perhaps the tutor being the client had something to do with that dialogue becoming more formal! With the asynchronous nature of e-mail there was uncertainty during the IDP as to whether emails had arrived and there was no guarantee of an immediate reply. In some instances, when response times were not fast enough, communications began to break down and "time was wasted in waiting for replies". To counter this, groups communicated online several times a day, some groups requesting emails be directed to both home and workplaces as well, allowing work to continue into the evening. Most groups soon exposed the limitations of using e-mail as the sole communications medium and had concerns over the nature of text only communication when applied to graphical concepts. Textual communication had to be precise, selfexplanatory and unambiguous and often tended to be over verbose in order to achieve clarity. It soon became apparent that the ability to attach drawings and sketches (as files) was extremely useful as these could describe much more. 


\section{Synchronous Communication}

Real-time desktop conferencing offered a better level of communication. Initially the IDP relied on 'Netscape Communicator' for these real-time sessions but latterly Microsoft Office's NetMeeting was used (as it offers audio \& video conferencing using a web cam). The software was mounted on two groups of PCs situated at geographically remote sites on campus. Early in the project the systems were demonstrated to the students and some time was set aside for them to investigate and experiment with the functionality. Each group was subsequently required to carry out a minimum of three sessions of real time communications with their clients in order to -

- show images of precedents and begin to develop the brief

- develop an aspect of the scheme online, and,

- discuss the final scheme.

Students were also required to carry out real-time sessions within their design teams on the Department computers. Very few students entered into real time communication away from the university instead choosing to carry out the majority of their remote online communication asynchronously via email and file attachments.

The students mainly used the chat facility and the whiteboard of 'Communicator' and subsequently NetMeeting. The whiteboard was used for real-time sessions both amongst the design team and between the client and the design team, usually by importing and then annotating drawings (Jpegs) created on other CAD software. This ability proved "a highly effective and user friendly method of communication" in the exchanging of information . The drawing tools supplied with the whiteboard were rather primitive and best used only for marking up drawings created in more sophisticated packages. The students often used the text directly onto the whiteboard to add comments to the drawings rather than opening up additional text boxes which often reduced the size of available viewable window on the screen.

Having text and drawings visible at the same time seemed essential for the development of the proposals. One criticism of working on the whiteboard was the difficulty in knowing who was in control and the students quickly had to establish a set of procedures for writing, drawing, and taking turns. One student found, "It was more effective using text messages on the whiteboard and drawing at the same time" whilst another found it simpler to keep the discussion to the 'chat' window whilst viewing the drawing on the whiteboard simultaneously. (fig. I)



fig.1 : development of proposals using 'Communicator's' whiteboard and 'chat' simultaneously 
Students had to establish 'new rules' for working in this environment particularly associated with the visually intensive field of the built environment. When using the whiteboard some groups agreed upon a colour coding system for textual clarity. Codes were established for ending messages in chat sessions in order not to waste too much time anticipating a longer response. Students were often misunderstood when engaging in their virtual communications. Difficulties were overcome in the strategic wording of communications by using humour and adopting a more informal approach to communications. Students experienced "it is easier to ignore, cut-off or dominate the other person in a virtual setting."

\section{Video Conferencing}

Subsequent developments of the IDP, as a result of student demand, have explored the use of audio and video conferencing. The IDP now uses Microsoft's 'NetMeeting' to conduct all online communications. Most students agreed that audio communication in conjunction with the whiteboard was a fairly effective means of conveying design ideas from the designer to the client. Video capabilities, using two remote PCs and web cams, on the other hand, were felt to be rather crude. Even over an intranet speech lagged behind the image causing dissatisfaction. The quality of drawings viewed via the video camera was also extremely poor forcing the students back to the whiteboard. Despite proving less useful for developing the designs, students noted their enjoyment of the video sessions. They realised the importance of audio and video in the conveying of expression and meaning to communication, something which text-based conferencing alone cannot quite so effectively do.

\section{Web Log and Web Diary}

In addition to the communications aspect of the project the students were required to create a web diary of daily events, noting the group's responsibilities and the development of the project (fig.2).

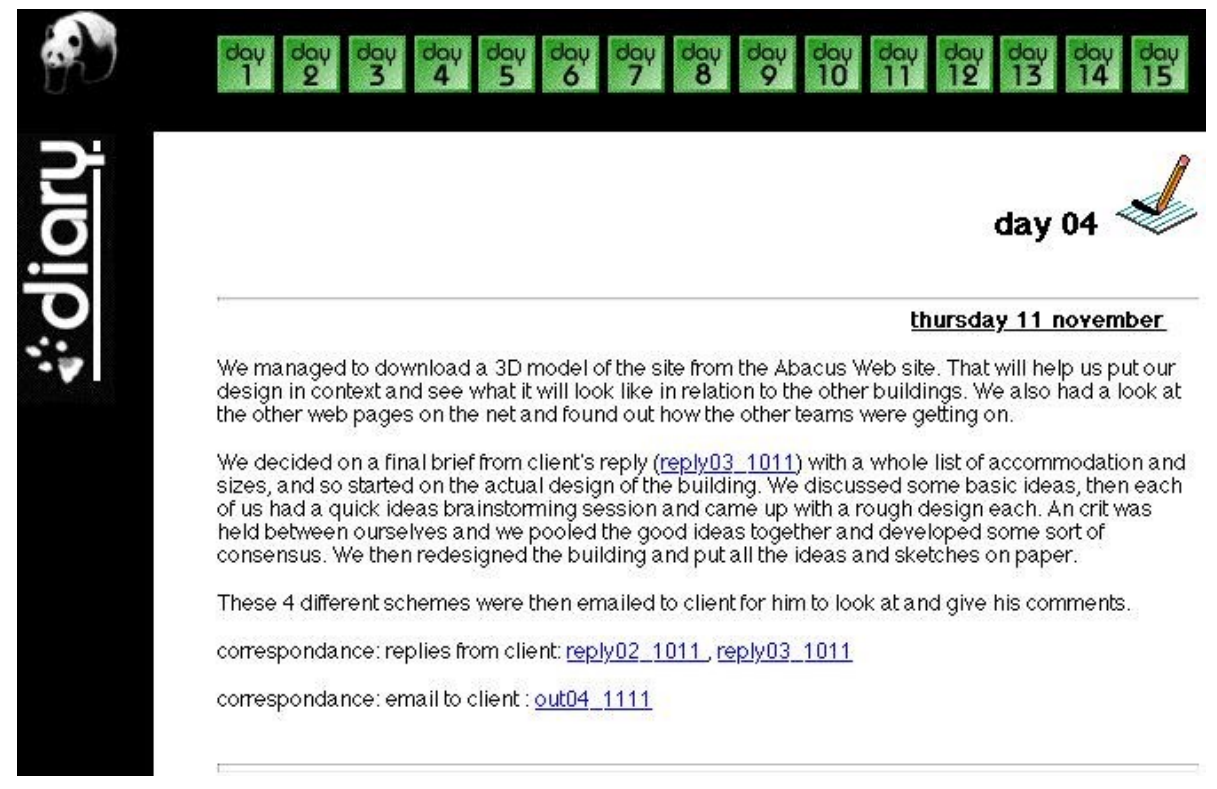

fig. 2 : diary entry outlining daily activities, presented on the web

To support this, each group had web space on the Departmental server (referred to as the web log) created for them by a CAD technician to upload all communications, text, notes, images, etc to. They were instructed in the uploading of the information using simple ftp software and only each design team's members and their tutor had access to their own logs throughout the project. The log was then edited to produce a diary of daily events, communications and development. This was to simulate the keeping of a diary of project events in practice. Some students found this 'useful in helping organise information and emails' but most found it '...tedious and over laborious'; 'a chore and hassle'. This aspect has been eliminated from the project and now the students set up joint e-mail accounts and delegate individuals in the group responsible for storing data, images, etc on their computers until presentation time. 


\section{Working Methods}

Examination of these web logs and diaries allowed staff an insight into the students' working methods and patterns. Although the project focussed on the experience of using internet technologies to progress a design project with a client, students were encouraged to meet face-to-face at points they thought necessary. Foreign students met face-to-face almost daily with other students meeting every 2-3 days.

In the earlier years of the IDP more emphasis was on the communication and the use of the tools, so face-to-face was less. The purposes of the online sessions (email and real-time) were identified by the students as -

- reviewing of different proposals;

- discussing the development of the project;

- emailing ideas;

- experiencing desktop conferencing, and

- $\quad$ communicating with the client.

They now tend to use face-to-face to establish the project, assign work, identify roles and then use email and conferencing tools to progress the designs; 'meeting' almost daily with as many members of the design team as possible. The real-time online sessions were arranged in a number of ways - face-to-face or via email or mobile phone. The better teams would elect a person in charge of communications and group organising, ensuring there was an agenda to the sessions and that all electronic material, especially images, were ready to hand and in the right format.

Students were allowed to form their own groups and meet beforehand but were not encouraged to physically meet the 'client'. This proved extremely frustrating for a few groups - '...could not see the client in person - very frustrating'. Students who knew each other prior to the IDP found that they could communicate better and express their ideas more openly than groups who had never met.

Groups who agreed a sub-division of tasks early on in the IDP created more harmonious working relationships, aiding communication significantly. They found that identifying the overall group objectives, identifying and prioritising the tasks necessary to achieve these objectives and specifying the group working procedures were essential activities to starting the project. Most groups would... 'capitalise on individual's strengths, each working on the areas he/she was best at. ' In nearly every group all students wanted to contribute to the design 'all worked on the brief \& design development'; 'whole team responsible for brief and design development.' This often caused conflicts within the groups. Groups which appointed leaders seemed to perform more successfully 'it was essential to have a good leader'.

The portion of time spent working in the department and elsewhere varied from group to group. Over the years it appears to average at about 50\% in the department and 50\% at home. Students have reported that 'group work was carried out mainly at university with individual tasks (drawings, research, presentation) done at home'.

\section{Barriers}

Barriers can be summarised within two main categories - technical and social -

- unreliable software;

- lack of technical training and support; and,

- $\quad$ not knowing collaborators in advance;

- not having clearly defined roles and responsibilities;

- misunderstandings in virtual space;

- frustration with asynchronous collaboration and differing student personalities.

Reflection and subsequent change to the programme over time has managed to overcome many of these barriers.

\section{Enablers and Benefits}

Introduced in direct response to increased student numbers, IDP's increasing reliance on peer learning is proving quite successful. The collaborative approach promotes a dynamic creative process whilst the production of the web diary offers a platform for documentation and reflection. University study maps professional practice by promoting team work skills; developing organisational skills and keeping up-to-date with new communications methods used in practice. The students on this programme will all be exposed to these technologies when they graduate; they will have the advantage of prior experience and first hand knowledge of problems involved when 
communicating in this mode. 'We can see how useful it could be in practice to link professionals at a distance' and '...useful in practice but will not supplant face-to-face meetings'.

\section{Evaluation}

The evaluation of the project involved a number of aspects -

- $\quad$ observing students carrying out project;

- $\quad$ communicating with students online to obtain progress updates;

- reviewing web logs (tutor access to web logs);

- $\quad$ attending final web presentation

- reviewing final scheme drawings;

- questioning students about experience; and,

- $\quad$ organising student feedback sessions and focus groups at the end of the project.

The students were very positive about the project - '...highlight of the year'; 'good fun sending messages'; 'worthy experience', but found the group work frustrating and often became annoyed if the technology didn't work. E-mail often proved frustrating in the time it took to receive a response, however real time sessions proved to be fast and effective and it was felt that the ability to 'send' a drawing and discuss its contents on a screen synchronously with a client or a designer was indeed an improvement on traditional methods of communication telephone, letter, fax.

Continued external examination of the course and association with industry helps to maintain QA and keep students informed of latest developments in professional practice. The IDP could be adapted easily, in part or whole, to other disciplines particularly those of the built environment.

\section{Learning Experiences}

A number of key issues became apparent as a result of the project.

- Physical distance becomes increasingly irrelevant when working collaboratively on design projects. One student noted how the designer and client (from disparate locations) could "pinpoint exact areas of discussion.... look at various design solutions, with immediate comment and counter comment" and then "agree on schematic design to be further developed by the designer, all very quickly."

- The IDP offered students new insights into alternative methods of working utilising communications technologies. They experienced some of the possibilities and limitations of the new communication tools shown to them and used various combinations to facilitate the development of their proposals.

- They had to establish 'new rules' for working in this environment in order not to be misunderstood.

- Each had the opportunity to develop skills in teamwork throughout the process of the project - essential for working in practice.

Recommendations and good practice for the implementation of similar projects Each year the IDP is re-evaluated and refined on the basis of what has been learnt over the preceding session. Several recommendations can be made from our experience of what makes a successful Internet Design Project -

- Establish all technologies well in advance, ensuring reliability.

- Update communications tools whenever possible. 'Netmeeting' is now used as it is a more 'all encompassing' 'low tech' piece of communication software. It allows for text communication, audio \& video conferencing, sharing of applications and collaborative browsing.

- Allow for technical hitches and have alternative methods of continuing project work.

- Allow students time to familiarise themselves with the software being used.

- Do not overestimate what can be achieved. Four weeks is a realistic time scale for what was expected.

- Inform the students of what to expect with team work and working in virtual environments.

- Establish procedures for working in this 'new environment'. This includes organising times to be online (and communicating).

- Try to maintain high levels of enthusiasm

\section{Conclusions}

Communications over a distance can be particularly difficult to sustain and it is significant that the most successful groups were those that kept up enthusiasm and worked co-operatively. 'Group interest was high which contributed to the success of our project.' The support of the educator is also essential in helping students 
in an online environment and by making the tutor part of the design process, ie the client, teams had an advisor ready at hand.

We found that true collaborative work necessitates a high level of feedback. Although email allowed the attachment of diagrams and other graphics, the inability to discuss these in real time hampered the collaborative design process. Synchronous collaboration, occurring 'same time, any place', provided a sense of immediacy, the ability to plan and solve problems and make decisions more quickly which proved very useful to the students. [5].

\section{Acknowledgements}

Dr. Michael Grant, Director of Computer-aided Building Design Course.

Charlie Brown, Chief Technician.

Peter Welsh, Part-time tutor.

\section{References}

1. M. Sclater, N. Sclater, L. Campbell, ICON : evaluating collaborative technologies Active Learning 7, (December 1997)

2. S.P. MacGregor, W.J.Ion, Introducing and developing virtual design environments - an effective platform for collaborative design projects in academia, Proceedings of EDE '99, University of Strathclyde, 243-247, (September 1999)

3. L. Harasim, S.R. Hiltz, L. Teles, M. Turoff, Learning Networks, MIT, Cambridge, Massachusetts (1997)

4. M.G. Moore, Three types of interaction, in K. Harry et al, Distance education: new perspectives, p.19-24, Routledge, London (1993)

5. O. Marjanovic, Learning and teaching in a synchronous collaborative environment. Journal of Computer Assisted Learning 15, 129-138 (1999) 